Journal of Islamic Medicine

Volume 2 (4) (2018), Pages 1-7

\title{
Pengaruh Teknik Relaksasi Genggam Jari Terhadap Tingkat Nyeri Pada Pasien Post Sectio Caesarea Di Ruangan Kebidanan Rumah Sakit Umum Daerah Poso
}

\author{
Fany Lairin Djala ${ }^{1}$, Dwi Yut Tahulending ${ }^{2}$ \\ ${ }^{1}$ Sekolah Tinggi Ilmu Kesehatan Husada Mandiri Poso \\ ${ }^{2}$ Program Studi Sarjana Keperawatan Stikes Husada Mandiri Poso \\ E-mail: fany_djala@yahoo.com
}

\begin{abstract}
Background: Based on the results of preliminary study in the midwife room of Poso District General Hospital through interview, nurse or midwife has never done relaxation technique of finger ginger on patient that has been done Sectio cesarean. Objective: To know the effect of hand-to-hand relaxation technique on the level of pain in post-cesarean section patients in the midwifery room of poso general hospital in 2017. Research Method: This research is a type of quasy experiment research with Design in this research is Quasi Experiment pre post test design with control group. The subjects of the study were postoperative patients of Sectio Caesarea who were admitted to midwifery room. The sample of research was taken by Accidental Sampling technique amounted to 32 respondents. Data were taken by using visual (visual rating scale) and univariate and bivariate data analysis using Wilcoxon statistic test with P-value value 95\% ( $\mathrm{p}=0,05)$. Result : There is Effect of Handheld Relaxation Technique on Finger Pain on Patient Post Sectio Caesarea ie $(p=0.000)$. Conclusion: There is effect of handheld relaxation technique on pain rate on patient post sectio caesarea.
\end{abstract}

Keywords: Pain, Post Patient Sectio Caesarea, Handheld Relaxation Technique

\begin{abstract}
Abstrak
Latar Belakang : Nyeri merupakan sesuatu yang tidak menyenangkan yang hanya dapat diungkapkan oleh individu yang mengalaminya. Salah satu terapi nonfarmakologi untuk mengatasi nyeri adalah tekhnik relaksasi genggam jari. Berdasarkan hasil studi awal yang di lakuakan di ruang kebidanan Rumah Sakit Umum Daerah Poso melalui wawancara, perawat atau pun bidan belum pernah melakukan teknik relaksasi gengam jari pada pasien yang telah di lakukan Sectio sesarea. Tujuan: Untuk mengetahui pengaruh teknik relaksasi genggam jari terhadap tingkat nyeri pada pasien post sectio caesarea di ruang kebidanan Rumah Sakit Umum Daerah Poso tahun 2017. Metode Penelitian : Penelitian ini merupakan jenis penelitian quasy experiment dengan desain pada penelitian ini adalah quasi Experiment pre post test design with control group. Subyek penelitian adalah pasien post operasi Sectio sesarea yang dirawat di ruang kebidanan. Sampel penelitian diambil dengan teknik Accidental Sampling berjumlah 32 responden. Data diambil dengan menggunakan visual (visual rating scale) dan analisis data dilakukan secara univariat dan bivariat menggunakan uji statistik Wilcoxon dengan nilai signifikansi P-value $95 \%(p=0,05)$. Hasil : Ada Pengaruh Teknik Relaksasi Genggam Jari Terhadap Tingkat Nyeri Pada Pasien Post Sectio Caesarea yaitu $(p=0,000)$. Kesimpulan: Terdapat pengaruh teknik relaksasi genggam jari terhadap tingkat nyeri pada pasien post sectio caesarea.
\end{abstract}

Kata Kunci : Nyeri, Pasien Post Sectio Caesarea, Teknik Relaksasi Genggam Jari 


\section{PENDAHULUAN}

Section caesarea adalah prosedur operatif melalui tahap anestesia sehingga janin, plasenta dan ketuban di lahirkan melalui insisi dinding abdomen dan uterus. Prosedur ini biasanya di lakukan setelah viabilitas tercapai dengan usia kehamilan lebih dari 24 minggu (1).

Berdasarkan data RISKESDAS tahun 2013, tingkat persalinan caesar di Indonesia 15,3\% Sampel dari 20.591 ibu yang melahirkan dalam kurun waktu 5 tahun terakhir yang diwawancara di 33 provinsi. Data Dinas Kesehatan Provinsi Sulawesi Tengah pada tahun 2012, dari jumlah ibu bersalin sebanyak 60,612 orang dengan penangganan komplikasi obstetrik sebanyak 7,261 orang atau 57,18\%, sedangkan pada tahun 2013 dari jumlah ibu bersalin 61,077 orang dengan penangganan komplikasi obstetrik sebanyak 7,294 atau 57,29\% (2).

Persalinan dengan Section caesarea dapat menimbulkan dampak setelah operasi yaitu nyeri yang di akibatkan oleh perubahan kontinuitas jaringan karena adanya pembedahan. Pada saat operasi di gunakan anestesi agar pasien tidak nyeri pada saat di bedah. Namun setelah operasi selesai dan pasien mulai sadar, akan merasakan nyeri di daerah sayatan yang membuat sangat terganggu (3).

Salah satu pengobatan non-farmakologis yang dapat dilakukan untuk mengatasi nyeri adalah teknik relaksasi genggam jari. Teknik mengenggam jari merupakan bagian dari teknik Jin Shin Jyutsu. Jin Shin Jyutsu adalah akupresur Jepang. Bentuk seni yang menggunakan sentuhan sederhana tangan dan pernafasan untuk menyeimbangkan energi didalam tubuh. Tangan (jari dan telapak tangan) adalah alat bantuan sederhana dan ampuh untuk menyelaraskan dan membawa tubuh menjadi 2 seimbang. Setiap jari tangan berhubungan dengan sikap sehari-hari. Ibu jari berhubungan dengan perasaan khawatir, jari telunjuk berhubungan dengan ketakutan, jari tengah berhubungan dengan kemarahan, jari manis berhubungan dengan kesedihan, dan jari kelingking berhubungan dengan rendah diri dan kecil hati (4).

Berdasarkan penelitian yang telah dilakukan oleh Ma'arifah dan Susanti tahun 2017 tentang Pengaruh Teknik Relaksasi Genggam Jari Terhadap Perubahan skala Nyeri Pada Pasien Post Operasi Sectio Caesarea di RSUD Prof. Dr. Margono menemukan ada pengaruh teknik relaksasi genggam jari terhadap perubahan skala nyeri pada pasien post operasi section caesarea. (5) 
Dari hasil wawancara yang di lakukan di dan ruang kebidanan Rumah Sakit Umum Daerah Poso, perawat atau pun bidan belum pernah melakukan teknik relaksasi gengam jari pada pasien yang telah di lakukan Sectio sesarea. Di ruang kebidanan Rumah Sakit Umum Daerah Poso penanganan nyeri menggunakan pendekatan farmakologi, biasanya dengan diberikan analgetik (injeksi ketorolac $1 \mathrm{amp}$ ), namun penggunaan analgesik secara terus menerus dapat mengakibatkan ketagihan obat. Meskipun sudah diberikan analgesik pasien masih merasakan nyeri. Dibutuhkan kombinasi antara farmakologi dan non farmakologi untuk mengontrol nyeri agar nyeri dapat berkurang.

\section{METODE}

Penelitian ini menggunakan rancangan penelitian pre post test design with control group dimana kelompok perlakuan dibagi menjadi dua yaitu kelompok Kontrol dan kelompok perlakuan yang dipilih secara Random. Sebelum diberikan perlakuan kedua kelompok tersebut diukur tingkat nyeriny dengan menggunakan Skala Nyeri Menurut Bourbanis dengan lima indikator yaitu tidak nyeri (skor 0), nyeri ringan (skor 1-3), nyeri sedang (skor 4-6), nyeri berat (skor 7-9) dan nyeri sangat berat (skor 10). Selanjutnya subyek perlakuan diberikan terapi teknik relaksasi genggam jari dan subyek kontrol tanpa perlakuan dan kemudian dilihat pengaruhnya melalui pengukuran skala nyeri. Sebelum dilakukan perlakuan diajukan persetujuan subjek. Waktu yang di butuhkan untuk menjelaskan dan mempraktikkan teknik relaksasi genggam jari yaitu 15 menit. Subjek di minta untuk mempraktikkan teknik relaksasi genggam jari selama 10 menit dan di ulang sebanyak 3 kali. Kemudian dilakukan penilaian tingkat nyeri.

\section{HASIL}

Tabel 1. Gambaran Intensitas Nyeri PreTest Kelompok Kasus dan Kelompok Kontrol di Ruangan Kebidanan Rumah Sakit Uumu Daerah Poso

\begin{tabular}{ccccc}
\hline \multirow{2}{*}{ Intensitas nyeri } & \multicolumn{4}{c}{ Pretest } \\
\cline { 2 - 5 } & $\mathrm{F}$ & $\%$ & $\mathrm{~F}$ & $\%$ \\
\cline { 2 - 5 } & 12 & 75.0 & 7 & 43.8 \\
\hline $4-6=$ Nyeri Sedang & 4 & 25.0 & 9 & 56.2 \\
$7-9=$ Nyeri Berat & 16 & 100 & 16 & 100 \\
\hline Total & 16 &
\end{tabular}


Tabel 2. Gambaran Intensitas Nyeri PostTest Kelompok Kasus dan Kelompok Kontrol di Ruangan Kebidanan Rumah Sakit Uumu Daerah Poso

\begin{tabular}{ccccc}
\hline \multirow{2}{*}{ Intensitas nyeri } & \multicolumn{4}{c}{ PostTest } \\
\cline { 2 - 5 } & \multicolumn{2}{c}{ Kasus } & \multicolumn{2}{c}{ Kontrol } \\
\cline { 2 - 5 } & $\mathrm{F}$ & $\%$ & $\mathrm{~F}$ & $\%$ \\
\hline 1-3 = Nyeri Ringan & 12 & 75.0 & 1 & 6.2 \\
$4-6=$ Nyeri Sedang & 4 & 25.0 & 8 & 50.0 \\
$7-9=$ Nyeri Berat & - & - & 7 & 43.8 \\
\hline Total & 16 & 100 & 16 & 100 \\
\hline
\end{tabular}

Berdasarkan gambaran intensitas nyeri sebelum dilakukan perlakuan (pre-test) pada tablel 1 bahwa pada kelompok kasus dari 16 responden mayoritas responden mengalami nyeri sedang yaitu sebanyak 12 orang $(75.0 \%)$, untuk kelompok kontrol dari 16 responden mayoritas responden mengalami nyeri berat yaitu sebanyak 9 orang (56.2\%). Kemudian setelah dilakukan perlakuan (Post-Test) pada tabel 2 menunjukkan

bahwa pada kelompok kasus dari 16 responden mayoritas responden mengalami nyeri ringan yaitu sebanyak 12 orang (75.0\%), untuk kelompok kontrol dari 16 responden mayoritas responden mengalami nyeri sedang yaitu sebanyak 8 orang $(50.0 \%)$

Berdasarkan hasil uji Wilcoxon Singned Rank Test di dapatkan nilai $P$-value $=0,000(\mathrm{P}<0,05)$ pada kelompok perlakuan yang berarti terdapat pengaruh teknik relaksasi genggam jari terhadap tingkat nyeri pada pasien post sectio caesarea di ruangan kebidanan Rumah Sakit Umum Daerah Poso. Pada kelompok kontrol ditemukan tidak adanya perubahan intensitas nyeri yang signifikan dimana nilai $P$-Value $=0,083(\mathrm{P}>0,05)$.

\section{PEMBAHASAN}

Adanya perubahan intensitas nyeri sebelum dan sesudah di lakukan teknik relaksasi genggam jari pada kelompok kasus dapat diketahui setelah di lakukan uji statistik menggunakan uji Wilcoxon Singned Rank Test pada tingkat kemaknaan 95\% ( $\mathrm{p}=0,05)$. Nyeri merupakan sesuatu yang tidak menyenangkan yang hanya dapat diungkapkan oleh individu yang mengalaminya (bersifat subjektif) dan persepsinya berbeda antara satu orang dengan orang lainya. (6). Luka yang terdapat dari perut akibat pembedahan menyebabkan nyeri yang dirasakan ibu post partum dengan Sectio Caesarea (7). Nyeri merupakan suatu mekanisme bagi 
tubuh, dimana akan timbul ketika jaringan mengalami kerusakan, sehingga berakibat individu tersebut bereaksi untuk menghilangkan rangsangan nyeri. (8)

Intervensi secara umum untuk pengelolaan nyeri yang tepat dan sesuai dengan pedoman dari WHO seperti penggunaan medikasi farmakologis yang tepat, pemberian terapi relaksasi maupun distraksi, serta terapi musik klasik yang telah dilakukan penelitian oleh beberapa ahli (9). Salah satu pengobatan non-farmakologis yang dapat dilakukan adalah teknik relaksasi genggam jari. Efek relaksasi genggam jari membuat responden merasa rileks dan tenang. Responden menjadi rileks dan tenang Perlakuan relaksasi gengam jari akan menghasilkan implus yang di kirim melalui serabut saraf aferen non nosiseptor. Serabut saraf aferen non nosiseptor mengakibatkan "pintu gerbang" tertutup terhambat sehingga stimulus nyeri terlambat dan berkurang (10) Teori Gate Control oleh Melzak dan Wall menyatakan bahwa impuls nyeri dapat diatur dan dihambat oleh mekanisme pertahanan di sepanjang system saraf pusat (SSP) dimana impuls nyeri dihantarkan saat sebuah pertahanan dibuka dan dihambat ketika sebuah pertahanan tertutup. Sehingga salah satu upaya untuk menghambat terjadinya penutupan pertahanan yang menjadi dasar teori menghilangkan nyeri tersebut yaitu melalui tehknik relaksasi. (11). Tehknik relaksasi juga dapat menurunkan kadar hormon stress yaitu Kortisol, menurunkan sumbersumber depresi sehingga nyeri dapat terkontrol dan fungsi tubuh semakin membaik. (12)

Penelitian ini di dukung oleh Pinandita, dkk (2012) dengan judul "Pengaruh teknik relaksasi genggam jari terhadap penurunan intensitas nyeri pada pasien post operasi laparatomi. Hasil penelitian menunjukkan $\mathrm{p}$-value $=0.000$, dimana nilai $(\mathrm{p}<0,05)$ yang berarti terdapat pengaruh dari teknik relaksasi genggam jari terhadap penurunan intensitas nyeri pasien pasca laparatomi. (10). Penelitian yang dilakukan oleh Haniyah, dkk (2016) dengan judul" Efektifitas Teknik Relaksasi Genggam Jari Terhadap Nyeri Post Sectio Caesarea Di RSUD Ajibarang dimana hasil penelitian menunjukkan $p$-value $=0.000$, dimana nilai $(\mathrm{p}<0,05)$, artinya terdapat efektifitas teknik relaksasi genggam jari terhadap nyeri post sectio caesarea di RSUD Ajibarang.(13). 


\section{KESIMPULAN}

Berdasarkan hasil penelitian ini maka dapat disimpulkan : a). intensitas nyeri pada pada responden sebelum dilakukan terapi genggam jari sebagian besar mengalami nyeri sedang. b). intensitas nyeri pada pada responden sesudah dilakukan terapi genggam jari sebagian besar mengalami nyeri ringan. c). Teknik relaksasi genggam jari dapat menurunkan tingkat nyeri pada pasien post sectio caesarea.

\section{DAFTAR PUSTAKA}

1. Myles. Buku Ajar Bidan. Jakarta : Buku Kedokteran EGC. 2011

2. Dinas Kesehatan Provinsi Sulawesi Tengah. Profil Dinas Kesehatan Provinsi Sulawesi Tengah tahun 2013. Palu. 2013

3. Penny simkin, janet Whalley, dan Ann kappler .Panduan lengkap. Ketrampilan Dasar Praktek Klinik Kebidanan. Jakarta : Slemba Mediaka. 2008

4. Hill, R. Y. Nursing from the inside-out:Living and nursing from the highest point of your consciousness. Jones and Barlett Publishers : London. 2011

5. Ma'arifah, Atun Raudotul., Susanti, Indri heri. Pengaruh Teknik Relaksasi Genggam Jari Terhadap Perubahan skala Nyeri Pada Pasien Post Operasi Sectio Caesareadi Rsud Prof. Dr. Margono Soekardjo. STIKes harapan Bangsa : Purwekerto. 2017

6. Prasetyo, Sigit Nian. Konsep dan Proses Keperawatan Nyeri Edisi Pertama. Graha Ilmu : Yogyakarta. 2010

7. Fitri, Mila., Mira, Trisyani \& Maryati, Ida. Hubungan Intensitas Nyeri Luka Sectio Caesarea Dengan Kualitas Tidur Pada Pasien Post Partum Hari Ke-2 Di Ruang Rawat Inap RSUD Sumedang. Fakultas Ilmu Keperawatan Universitas Padjadjaran : Bandung. 2012

8. Maryunani, A. Nyeri dalam Persalinan, Teknik dan Cara Penanganannya. Trans Info Media Jakarta. 2010

9. Saifuddin, Abdul Bari. Buku Panduan Praktis Pelayanan Kesehatan Maternal dan Neonatal. Yayasan Bina Sarwono Prawirohardjo :Jakarta. 2006

10. Pinandita, I., Purwanti, E, \& Utoyo, B. Pengaruh Teknik Relaksasi Genggam Jari Terhadap Penurunan Intensitas Nyeri Pada Pasien Post Operasi Laparatomi. Jurusan Keperawatan STIKes Muhammadiyah Gombong. 2012

11. Melzack \& Wall. Teori Gerbang Nyeri, cetakan ketiga. Jakarta. 1999

12. Potter \& Perry. Buku Ajar Fundamental Keperawatan : Konsep, Proses dan Praktik.Volume 2, Edisi 4, EGC, Jakarta. 2005 
13. Haniyah, S., Setyawati, Martyarini Budi., Sholikhah, Siti Mar'atus. Efektifitas Teknik Relaksasi Genggam Jari Terhadap Nyeri Post Sectio Caesarea Di RSUD Ajibarang. STIKes Harapan Bangsa: Purwokerto. 2016 